\title{
Comorbid Symptoms of Internet Addiction Among Adolescents with and Without Autism Spectrum Disorder: A Comparative Study
}

Kentaro Kawabe

Ehime University

Fumie Horiuchi ( $\triangle$ matsufu15@hotmail.com )

Ehime University

Rie Hosokawa

Ehime University

Kiwamu Nakachi

Ehime University

Junya Soga

Ehime University

Shu-ichi Ueno

Ehime University

\section{Research Article}

Keywords: autism spectrum disorder, gaming disorder, Internet addiction, adolescents, pathological Internet use

Posted Date: December 14th, 2021

DOI: https://doi.org/10.21203/rs.3.rs-1122880/v1

License: (c) (i) This work is licensed under a Creative Commons Attribution 4.0 International License. Read Full License 


\section{Abstract}

Over the last decade, research into the characteristics of problematic internet use among individuals with autism spectrum disorder (ASD) has greatly increased. We investigated Internet addiction's prevalence and compared its related factors, among adolescents with and without ASD. Outpatients $(n=102)$ aged 12-15 years, completed the Basic Information Questionnaire, Internet Addiction Test, and Quick Inventory of Depressive Symptomatology Self-Report Japanese version. Their parents completed the Social Responsiveness Scale-2 and Attention Deficit Hyperactivity Disorder Rating Scale-IV. Scores of both (ASD and without ASD) groups were analyzed. Prevalence of Internet addiction was $40.0 \%$ in ASD group and $23.9 \%$ in without ASD group. Statistically related factors of Internet addiction were not found in the ASD group. However, factors of Internet addiction were related to the QIDS and ADHD-RS scores in the without ASD group. In conclusion, factors related to Internet addiction differed for ASD patients and without ASD patients.

\section{Introduction}

Over the last decade, internet tools have become a fast-growing recreational activity not only among adolescents and young adults, but also among people of all ages. The Internet allows easy, and often free, access to playable online games. Digital devices with Internet allow communication across online communities and product review sites, using instant messaging, voice chat, social network services (SNS), etc. Recently, many people started using the Internet for variety and interesting virtual communications, as well as social interaction with friends in the real world. Moreover, individuals use SNS and online gaming to alleviate negative feelings, such as sadness, feeling low, loss of interest in daily activities. These facts indicate that the Internet is a critical part of our lives; however, it also has several negative effects, such as uncontrollable, problematic use, and Internet addiction. Internet addiction is defined by excessive and problematic internet use and clinical features of behavioral addiction: preoccupation, compulsive behavior, lack of control, and functional impairment (Young, 1996). It is associated with various psychosocial issues. Moreover, psychological issues or stressful events may play a role in the etiology of Internet addiction. Internet addiction has been linked to extreme real-life social withdrawal among adolescents and young adults (Stavropoulos et al., 2019). In addition, problematic internet use for online gaming is the most common cause of internet addiction and serious problem in many countries (Chia et al., 2020). The American Psychiatric Association (APA) specifies Internet addiction as "Internet gaming disorder" (IGD) in Section III of the fifth edition of the Diagnostic and Statistical Manual of Mental Disorders (DSM-5) (American Psychiatric Association, 2013). The World Health Organization (WHO) has also lists "Gaming Disorder" as a substance use and addictive disorder in the eleventh edition of International Classification of Diseases (ICD-11) (World Health Organization, 2018).

According to a systematic review conducted in 2020, the prevalence of Internet addiction is $7.0 \%$ in the general population (Pan et al., 2020). Another meta-analysis found that the pooled prevalence rate of Internet addiction in Southeast Asia was 20.0\% (Chia et al., 2020). According to high-quality evidence, 
Internet addiction is moderately associated with attention deficit hyperactivity disorder (ADHD) and depression (Wang et al., 2017; Tokunaga, 2017; Normand et al., 2021; Zhou et al., 2020; Seki et al., 2019). Recent studies have reported a higher prevalence of problematic internet use among individuals with autism spectrum disorder (ASD), although factors related to problematic internet use are not clear (Normand et al., 2021; Murray et al., 2021). ASD is a group of heterogeneous conditions characterized by deficits in social communication and social interactions, and by the presence of restrictive and repetitive patterns of behaviors, interests, or activities (American Psychiatric Association, 2013). Among children with ASD, over $70.4 \%$ were diagnosed with at least one comorbid psychiatric disorder and $41.1 \%$ had multiple comorbidities (Lundström et al., 2015; Simonoff et al., 2008). This suggests that Internet addiction is one of the comorbid psychiatric disorders among ASD patients (Hirota et al., 2021). However, research related to the comparison of factors related to Internet addiction among adolescents with and without ASD is very limited. Therefore, we hypothesized that Internet use among adolescents with ASD differs from that among adolescents without ASD.

\section{Results}

Participants' demographics and characteristics are presented in Table 1. The SRS-2 and ADHD-RS scores were significantly higher in the ASD group $(p<0.001)$ than in the without ASD group $(p=0.02)$. Based on IAT scores, the prevalence of Internet addiction was $40.0 \%$ in the ASD group (14/35, 95\% Cl: $23.9-57.9 \%)$, and $23.9 \%(16 / 67,95 \% \mathrm{Cl}: 14.3 \%-35.9 \%)$ in the without ASD group. There were no significant differences in the prevalence of Internet addiction between the ASD and without ASD groups $(p=0.09)$. No significant differences were observed in the number of participants to whom each electronic device was freely accessible between the ASD and without ASD groups.

Table 1 Demographics and characteristics of participants 


\begin{tabular}{|c|c|c|c|c|}
\hline & $\begin{array}{l}\text { ASD, } \\
\mathrm{n}=35\end{array}$ & $\begin{array}{l}\text { without ASD, } \\
n=67\end{array}$ & $\varphi$ or R & $\mathbf{P}$ \\
\hline Sex & & & -0.19 & 0.06 \\
\hline Male & $21(60.0)$ & $27(40.6)$ & & \\
\hline Female & $14(40.0)$ & $40(59.4)$ & & \\
\hline Grade & & & 0.13 & 0.42 \\
\hline $7^{\text {th }}$ & $13(37.1)$ & $19(27.5)$ & & \\
\hline $8^{\text {th }}$ & $12(34.3)$ & $32(47.8)$ & & \\
\hline $9^{\text {th }}$ & $10(28.6)$ & $16(24.6)$ & & \\
\hline SRS & $67.83(29.11)$ & $42.81(18.87)$ & -0.40 & $<0.001 * \star \star$ \\
\hline ADHD-RS & $12.11(8.86)$ & $7.77(7.93)$ & -0.24 & $0.02 *$ \\
\hline IAT score & $46.26(19.79)$ & $40.96(14.65)$ & 0.10 & 0.26 \\
\hline Internet addiction & $14(40.0)$ & $26(23.9)$ & 0.17 & 0.09 \\
\hline Severity & & & 0.19 & 0.17 \\
\hline IAT score; $\geq 70$ & $5(14.3)$ & $3(4.5)$ & & \\
\hline IAT score; 40-69 & $15(42.9)$ & $27(40.3)$ & & \\
\hline QIDS score & $7.57(5.94)$ & $8.78(6.39)$ & 0.09 & 0.37 \\
\hline Depression & $7(20.0)$ & $26(38.8)$ & -0.19 & 0.05 \\
\hline \multicolumn{5}{|l|}{ Electric devices } \\
\hline Television & $29(82.9)$ & $56(83.6)$ & -0.07 & 0.46 \\
\hline Laptop computer & $17(48.6)$ & $30(44.8)$ & 0.05 & 0.61 \\
\hline Tablet & $16(45.7)$ & $27(40.3)$ & 0.04 & 0.71 \\
\hline Smartphone & $21(60.0)$ & $45(67.2)$ & -0.06 & 0.56 \\
\hline Video games & $27(77.1)$ & $47(70.1)$ & 0.09 & 0.41 \\
\hline
\end{tabular}

Values expressed as $N(\%)$ or mean \pm SD; Internet addiction, IAT score $\geq 50$; Depression, QIDS score $\geq 11$; ${ }^{*} \mathrm{p}$ value $<0.05,{ }^{*} \mathrm{p}$ value $<0.01, * \star \star \mathrm{p}<0.005$

The results of multiple linear regression analysis revealed that no potential risk factors were statistically significant in the ASD group (Table 2). 
Table 2 Possible contributing factors to IAT score in ASD group

\begin{tabular}{|c|c|c|c|c|c|c|}
\hline & ASD & & & & & \\
\hline Model & B & $95 \% \mathrm{Cl}$ & $\mathrm{t}$ & $\mathrm{p}$ & Tolerance & VIF \\
\hline Male & -2.24 & $-18.67-14.19$ & -0.28 & 0.78 & 0.81 & 1.23 \\
\hline Grade & -2.02 & $-11.05-7.00$ & -0.46 & 0.65 & 1.00 & 1.00 \\
\hline QIDS & -0.12 & $-1.57-1.33$ & -0.17 & 0.87 & 0.74 & 1.36 \\
\hline SRS & 0.11 & $-0.27-0.49$ & 0.60 & 0.56 & 0.45 & 2.23 \\
\hline ADHD-RS & -0.52 & $-1.74-0.70$ & -0.87 & 0.39 & 0.46 & 2.16 \\
\hline
\end{tabular}

Cl: confidence interval; Multiple linear regression analysis coefficients table

However, the QIDS $(B=0.94, p=0.001)$ and ADHD-RS $(B=0.74, p=0.003)$ scores were significantly correlated with IAT scores among the without ASD group (Table 3 ).

Table 3 Possible contributing factors to IAT score in without ASD group

\begin{tabular}{|c|c|c|c|c|c|c|}
\hline & witho & ASD & & & & \\
\hline Model & B & $95 \% \mathrm{Cl}$ & $\mathrm{t}$ & $\mathrm{p}$ & Tolerance & VIF \\
\hline Male & 3.31 & $-3.79-10.40$ & 0.93 & 0.36 & 0.83 & 1.21 \\
\hline Grade & 2.31 & $-2.22-6.85$ & 1.02 & 0.31 & 0.99 & 1.01 \\
\hline QIDS & 0.94 & $0.41-1.47$ & 3.54 & $0.001^{\star * *}$ & 0.86 & 1.17 \\
\hline SRS & -0.13 & $-0.33-0.07$ & -1.28 & 0.21 & 0.70 & 1.43 \\
\hline ADHD-RS & 0.74 & $0.26-1.22$ & 3.09 & $0.003^{* * *}$ & 0.70 & 1.43 \\
\hline
\end{tabular}

$\star \star \star x<0.005 ;$ Cl: confidence interval; Multiple linear regression analysis coefficients table

\section{Discussion}

The current study examined the factors related to Internet addiction among junior high school students who visit psychiatric clinics. To our knowledge, this is the first study to investigate the characteristics of psychiatric patients with and without ASD among junior high school students.

In the present study, the prevalence of Internet addiction was $40.0 \%$ among adolescents with ASD and $23.9 \%$ among adolescents without ASD in the outpatient psychiatric clinic. A previous study reported that the prevalence of Internet addiction among junior high school students was $16.3 \%$ (86/529, 95\% Cl: 13.2-19.7\%) (Kawabe et al., 2016). Another study reported that the prevalence of Internet addiction 
among adolescents with ASD was $38.6 \%$ based on an IAT cutoff score of 50; similar results were found in this study (Masi et al., 2020). A previous study reported a higher prevalence (45.5\%) of Internet addiction among adolescents with ASD, however, that study included ASD patients with comorbid ADHD (Kawabe et al., 2019). Internet addiction has been associated with ADHD diagnosis and ADHD traits (Wang et al., 2017; Tokunaga, 2017). Therefore, in this study, we excluded participants with ADHD. In the current study, the considerably higher prevalence among participants with ASD than in the general population suggests that adolescents with ASD have a higher rate of Internet addiction. This study also showed the prevalence of Internet addiction among adolescents with mild psychiatric disorders such as adjustment disorder, somatic symptoms disorder, and sleep disorder. They had slightly higher rate of Internet addiction than the general population.

The results of multiple regression analyses revealed that no potential risk factors for Internet addiction were found to be statistically significant in the ASD group. Self-reported results indicated that participants with ASD tended to be more addicted to the Internet than participants without ASD, although factors related to Internet addiction changed between the two groups. A recent systematic review indicated that internal factors (sex differences, ASD symptom severity, age) and external factors (social aspects of video gaming: playing in multiplayer mode, access to video game systems, parent-child relationships) are significant predictors of problematic video game use among individuals with ASD (Craig et al., 2021). In terms of sex differences, males play video games more frequently than females, whereas females use SNSs more frequently. Therefore, there is no consensus on whether Internet addiction is associated with gender differences (Su et al., 2020). Individuals with ASD have trouble interpreting complex social interactions and intentions and are unable to make quick judgments in social contexts. This further undermines their social interactions with peers (Masten et al., 2011). Engelhardt et al. reported that individuals with ASD have characteristics such as highly restricted interests and social deficits, which in turn can lead to a greater risk of excessive use of video games (Engelhardt et al., 2017). In this study, we investigated the severity of ASD symptoms using the SRS-2, which is not related to the symptoms of Internet addiction in ASD. Although Internet addiction is associated with deficits in social communication and avoidance of social contact, it may not be important. Factors related to Internet addiction might be more diverse in case of individuals with ASD (Jiao et al., 2017). Paulus et al. suggested that if an individual with ASD has developed Internet addiction, it should be treated as a comorbid diagnosis (Paulus et al., 2020). To date, there is no tool that distinguishes between restricted interests or repetitive behaviors and Internet use in individuals with ASD (Craig et al., 2021). Therefore, clinicians should consider the possibility of comorbid Internet addiction among ASD patients and use various evaluation scales and diagnostic criteria to measure Internet addiction and gaming disorders.

In addition, our results suggest that the association between, both, depressive states and Internet addiction, and ADHD score and Internet addiction were observed only in the without ASD group. Some studies have shown the association between ADHD characteristics, traits, and Internet addiction (Wang et al., 2017; Zhou et al., 2020; Tateno et al., 2018). In addition, another study has shown the association between depressive state and Internet addiction (Tokunaga, 2017). These results support the findings of the present study. Furthermore, according to several epidemiologic studies, there is a strong association 
between depressive symptoms and Internet addiction (Li et al., 2019; Moreno et al., 2021). People with loneliness tend to prefer socializing on the Internet, which leads to the overuse of social networking sites (Ndasauka et al., 2016). Peer relationships are also important predictors of Internet addiction, although whether pathological social withdrawal creates Internet addiction, or Internet overuse creates peer relationships remains unclear (Strittmatter et al., 2016; Kato et al., 2020).

Our study has several limitations. First, the participants were chosen from a single center in Japan, which might not be representative of all adolescents. Therefore, the generalizability of our findings is limited. Second, the sample size was relatively small. Third, we did not control for confounding factors, such as economic status and academic performance. Finally, participants with moderate-to-severe psychiatric disorders and ADHD were excluded, which could have introduced selection bias.

In conclusion, this study indicated that factors related to Internet addiction differed for ASD patients and without ASD patients. Future research should carefully diagnose Internet addiction in patients with ASD to better understand the comorbidity with ASD.

\section{Methods}

\section{Aim}

This study investigates the prevalence of Internet addiction among adolescents with ASD and elucidates factors related to Internet addiction among adolescents with and without ASD.

\section{Participants and design}

Participants were adolescent outpatients at the Center for Child Health, Behavior and Development, Ehime University Hospital. This center is a specialized psychiatry outpatient clinic for children and adolescents where medical examinations are performed for almost 200 new patients annually. The study period was from January 2017 to December 2019, before the outbreak of the COVID-19 pandemic.

\section{Eligibility Criteria}

The inclusion criteria were as follows: Those 1 ) aged $12-15$ years, equivalent to being enrolled in $7^{\text {th }}-9^{\text {th }}$ grade; 2 ) who visited the hospital for the first time during the study period; 3 ) who signed informed consent forms and whose parents provided informed assent forms for study participation; 4) who were diagnosed with ASD based on the Autism Diagnostic Observation Schedule-2, Autism Diagnostic Interview-Revised, and DSM-5 criteria (American Psychiatric Association, 2013).

The exclusion criteria were as follows: Those 1) unable to fully comprehend and respond to questionnaires because of moderate-to-severe intellectual disabilities or severe psychiatric disorders, such as schizophrenia and anorexia nervosa, as screened by psychiatrists; 2) who were diagnosed with depressive disorders or ADHD based on the DSM-5 criteria (American Psychiatric Association, 2013). 
According to the eligibility criteria, 102 participants (equivalent, 51.0\%) were included in this study (Fig. 1). Participants were divided into two separate groups: adolescents with ASD and those without ASD.

\section{Instruments}

Participants completed the basic information questionnaire, Young's Internet Addiction Test (IAT) (Young, 1996), and the Quick Inventory of Depressive Symptomatology Self-Report (Rush et al., 2003) Japanese version (QIDS-J). Simultaneously, parents of participants responded to the Social Responsiveness Scale2 (SRS-2) (Constantino \& Gruber, 2012) and ADHD Rating Scale-IV (ADHD-RS) (Tani et al., 2010).

\section{Basic Information Questionnaire}

The basic information questionnaire included questions regarding sex, school grade, and usage of electronic devices, such as Television, Laptop, Computers, Tablets, Smartphones, and Video game consoles. Participants also responded to the question: "Are electronic devices freely accessible to you?" with "Yes" or "No."

\section{Internet Addiction Test}

The IAT comprises 20 items and is calibrated with scores between 1 and 5 , with total scores ranging from 20 to 100 . Higher scores reflect a greater tendency toward addiction. Total scores $\geq 70$ are classified as severe Internet addiction and between 40-69 as possible Internet addiction (Young, 1996). In this study, the Internet addiction group was classified as those obtaining an IAT score $\geq 50$, while the non-Internet addiction group was classified as those obtaining IAT score $\leq 49$. This classification was based on several previous studies that defined mild and severe Internet addiction with an IAT score $\geq 50$ (Malak et al., 2017; Tateno et al., 2018). In the present study sample $(n=102)$, the Cronbach's a coefficient was 0.93 .

\section{Quick Inventory of Depressive Symptomatology Self-Report-Japanese version}

We used the QIDS-J to evaluate the severity of depression in each patient. The total score ranges from 0 to 27 , with higher scores indicating a higher severity of depression. Individual scores are interpreted as $0-$ 5 (none), 6-10 (mild severity), 11-15 (moderate severity), 16-20 (severe), and 21-27 (very severe) (Rush et al., 2003). Thus, a cut-off score of 11 is considered to indicate moderate or severe levels of depression. Both the validity and reliability of the QIDS-J have been established previously (Trivedi et al., 2004). In the present study sample $(n=102)$, Cronbach's a coefficient was 0.85 .

\section{Social Responsiveness Scale-2}

The SRS-2 is a 65-item parent-rated questionnaire that evaluates the child's autistic traits in terms of social communication, awareness, motivation, cognition, and behavior flexibility within the past six months. Items are rated on a 4-point Likert scale (ranging from 0 to 3), with higher scores indicating more autistic traits (Constantino \& Gruber, 2012). 


\section{ADHD Rating Scale-IV}

The ADHD-RS is an 18-item questionnaire that reports the frequency of symptoms over the past six months on a 4-point Likert scale, measuring symptoms of ADHD according to the DSM-IV. The total scale scores range from 0 to 54 (Tani et al., 2010).

\section{Sample Size}

The sample size was calculated based on two-sample t-tests using the G*Power 3.1.9.2 software (Faul et al., 2009). An effect size of 0.5 , a significance level of $a=0.05$, a statistical power of $1-\beta=0.8$, and a $1: 2$ allocation ratio between the ASD and without ASD groups were also considered. Sample size calculation was performed before initiating recruitment, and we set a total sample size of 114 participants.

\section{Statistical Analysis}

The study results are expressed as the mean \pm standard deviation (SD) for continuous variables and as numbers and percentages for categorical variables. Descriptive statistics were used to describe the distribution of participants' characteristics. Chi-square tests were used for categorical variables. We performed multiple linear regression analysis to explore the correlation between the IAT score and factors such as the QIDS score, ADHD-RS score, and SRS-2 score. All tests were two-sided, and the significance level was set at 5\%. All data were analyzed using SPSS Statistics software (version 23.0; IBM Corp., Armonk, NY, USA) for Windows and R version 4.1.0.

\section{Procedure}

The surveys were conducted using a self-report questionnaire and a parent-report questionnaire. The questionnaires were handed to the participants and their parents by a doctor during their first visit. Before the research, the doctor explained to participants and their parents that: 1) participation was voluntary, and 2) strict confidentiality would be maintained. Written informed consent and assent forms were obtained from the participants and their parents. The study was approved by the Institutional Review Board of the Ehime University Graduate School of Medicine (IRB No. 1507007). All participants signed an informed consent form in accordance with the Declaration of Helsinki.

\section{Declarations}

\section{Acknowledgements}

The authors are tremendously grateful to all the individuals and families who enrolled in this study, and staff in the Ehime University Hospital.

\section{Authors' contributions}

K. K. designed the study, managed data collection, conducted statistical analysis, and prepared the initial manuscript. F. H. contributed to the study design, data collection, statistical analysis, and critical revision 
of the manuscript for important intellectual content. K. N., R. H. and J. S. contributed to the data collection. S. U. provided critical comments that significantly enhanced the final draft. All authors read and approved the final manuscript.

\section{Funding}

This study was supported by a Grant-in-Aid for Scientific Research (20K18935).

\section{Competing interests}

The authors have no relevant financial or non-financial interests to disclose.

\section{Ethics approval}

This study was approved by the Institutional Review Board of Ehime University Graduate School of Medicine (IRB No. 1507007), and the research was carried out in accordance with the provisions of the World Medical Association Declaration of Helsinki.

\section{Consent to participate}

Written informed consent from parents and informed assent from participants were obtained.

\section{References}

1. American Psychiatric Association. (2013). Diagnostic and statistical manual of mental disorders: DSM-5 (5th ed.). Arlington, VA: American Psychiatric Publishing: Washington, DC.

2. Chia, D. X., Ng, C. W., Kandasami, G., Seow, M. Y., Choo, C. C., Chew, P. K., Lee, C., \& Zhang, M. W. (2020). Prevalence of internet addiction and gaming disorders in Southeast Asia: a meta-analysis. International journal of environmental research and public health, 17(7), 2582. https://doi.org/10.3390/ijerph17072582

3. Constantino, J. N., \& Gruber, C. P. (2012). Social responsiveness scale: SRS-2. Torrance, CA: Western Psychological Services.

4. Craig, F., Tenuta, F., De Giacomo, A., Trabacca, A., \& Costabile, A. (2021). A systematic review of problematic video-game use in people with Autism Spectrum Disorders. Research in Autism Spectrum Disorders, 82, 101726. https://doi.org/10.1016/j.rasd.2021.101726

5. Engelhardt, C. R., Mazurek, M. O., \& Hilgard, J. (2017). Pathological game use in adults with and without Autism Spectrum Disorder. PeerJ, 5, e3393. https://doi.org/10.7717/peerj.3393

6. Faul, F., Erdfelder, E., Buchner, A., \& Lang, A. G. (2009). Statistical power analyses using G* Power 3.1: Tests for correlation and regression analyses. Behavior research methods, 41, 11491160. https://doi.org/10.3758/BRM.41.4.1149

7. Hirota, T., McElroy, E., \& So, R. (2021). Network analysis of internet addiction symptoms among a clinical sample of Japanese adolescents with autism spectrum disorder. Journal of Autism and 
Developmental Disorders, 51(8), 2764-2772. https://doi.org/10.1007/s10803-020-04714-x

8. Jiao, C., Wang, T., Peng, X., \& Cui, F. (2017). Impaired empathy processing in individuals with Internet addiction disorder: An event-related potential study. Frontiers in human neuroscience, 11, 498. https://doi.org/10.3389/fnhum.2017.00498

9. Kato, T. A., Shinfuku, N., \& Tateno, M. (2020). Internet society, internet addiction, and pathological social withdrawal: the chicken and egg dilemma for internet addiction and hikikomori. Current opinion in psychiatry, 33(3), 264-270. https://doi.org/10.1097/YC0.0000000000000601

10. Kawabe, K., Horiuchi, F., Miyama, T., Jogamoto, T., Aibara, K., Ishii, E., \& Ueno, S. I. (2019). Internet addiction and attention-deficit/hyperactivity disorder symptoms in adolescents with autism spectrum disorder. Research in developmental disabilities, 89, 22-

28. https://doi.org/10.1016/j.ridd.2019.03.002

11. Kawabe, K., Horiuchi, F., Ochi, M., Oka, Y., \& Ueno, S. I. (2016). Internet addiction: Prevalence and relation with mental states in adolescents. Psychiatry and clinical neurosciences, 70(9), 405412. https://doi.org/10.1111/pcn.12402

12. Li, X., Luo, X., Zheng, R., Jin, X., Mei, L., Xie, X., Gu, H., Hou, F., Liu, L., Luo, X., Meng, H., Zhang, J., \& Song, R. (2019). The role of depressive symptoms, anxiety symptoms, and school functioning in the association between peer victimization and internet addiction: A moderated mediation model. Journal of affective disorders, 256, 125-131. https://doi.org/10.1016/j.jad.2019.05.080

13. Lundström, S., Reichenberg, A., Melke, J., Råstam, M., Kerekes, N., Lichtenstein, P., Gillberg, C., \& Anckarsäter, H. (2015). Autism spectrum disorders and coexisting disorders in a nationwide Swedish twin study. Journal of Child Psychology and Psychiatry, 56(6), 702710. https://doi.org/10.1111/jcpp.12329

14. Malak, M. Z., Khalifeh, A. H., \& Shuhaiber, A. H. (2017). Prevalence of Internet Addiction and associated risk factors in Jordanian school students. Computers in Human Behavior, 70, 556563. https://doi.org/10.1016/j.chb.2017.01.011

15. Masi, G., Berloffa, S., Muratori, P., Paciello, M., Rossi, M., \& Milone, A. (2021). Internet addiction disorder in referred adolescents: a clinical study on comorbidity. Addiction Research \& Theory, 29(3), 205-211. https://doi.org/10.1080/16066359.2020.1772242

16. Masten, C. L., Colich, N. L., Rudie, J. D., Bookheimer, S. Y., Eisenberger, N. I., \& Dapretto, M. (2011). An fMRI investigation of responses to peer rejection in adolescents with autism spectrum disorders. Developmental Cognitive Neuroscience, 1(3), 260-270. https://doi.org/10.1016/j.dcn.2011.01.004

17. Moreno, M., Riddle, K., Jenkins, M. C., Singh, A., Zhao, Q., \& Eickhoff, J. (2021). Measuring Problematic Internet Use, Internet Gaming Disorder and Social Media Addiction in young adults: A cross-sectional study. JMIR Public Health and Surveillance. Doi: 10.2196/27719

18. Murray, A., Koronczai, B., Király, O., Griffiths, M. D., Mannion, A., Leader, G., \& Demetrovics, Z. (2021). Autism, problematic internet use and gaming disorder: A systematic review. Review Journal of Autism and Developmental Disorders, 1-21. https://doi.org/10.1007/s40489-021-00255-w 
19. Ndasauka, Y., Hou, J., Wang, Y., Yang, L., Yang, Z., Ye, Z., Hao, Y., Fallgatter, A. J., Kong, Y., \& Zhang, X. (2016). Excessive use of Twitter among college students in the UK: Validation of the Microblog Excessive Use Scale and relationship to social interaction and loneliness. Computers in Human Behavior, 55, 963-971. https://doi.org/10.1016/j.chb.2015.10.020

20. Normand, C. L., Fisher, M. H., Simonato, I., Fecteau, S. M., \& Poulin, M. H. (2021). A Systematic Review of Problematic Internet Use in Children, Adolescents, and Adults with Autism Spectrum Disorder. Review Journal of Autism and Developmental Disorders, 1-14. https://doi.org/10.1007/s40489-02100270-x

21. Pan, Y. C., Chiu, Y. C., \& Lin, Y. H. (2020). Systematic review and meta-analysis of epidemiology of internet addiction. Neuroscience \& Biobehavioral Reviews, 118, 612622. https://doi.org/10.1016/j.neubiorev.2020.08.013

22. Paulus, F. W., Sander, C. S., Nitze, M., Kramatschek-Pfahler, A. R., Voran, A., \& von Gontard, A. (2019). Gaming disorder and computer-mediated communication in children and adolescents with autism spectrum disorder. Zeitschrift für Kinder-und Jugendpsychiatrie und Psychotherapie, 48(2), 113122. https://doi.org/10.1024/1422-4917/a000674

23. Rush, A. J., Trivedi, M. H., Ibrahim, H. M., Carmody, T. J., Arnow, B., Klein, D. N., Markowitz, J. C., Ninan, P. T., Kornstein, S., Manber, R., Thase, M. E., Kocsis, J. H., \& Keller, M. B. (2003). The 16-Item Quick Inventory of Depressive Symptomatology (QIDS), clinician rating (QIDS-C), and self-report (QIDS-SR): a psychometric evaluation in patients with chronic major depression. Biological psychiatry, 54(5), 573-583. https://doi.org/10.1016/S0006-3223(02)01866-8

24. Seki, T., Hamazaki, K., Natori, T., \& Inadera, H. (2019). Relationship between internet addiction and depression among Japanese university students. Journal of affective disorders, 256, 668672. https://doi.org/10.1016/j.jad.2019.06.055

25. Simonoff, E., Pickles, A., Charman, T., Chandler, S., Loucas, T., \& Baird, G. (2008). Psychiatric disorders in children with autism spectrum disorders: prevalence, comorbidity, and associated factors in a population-derived sample. Journal of the American Academy of Child \& Adolescent Psychiatry, 47(8), 921-929. https://doi.org/10.1097/CHI.0b013e318179964f

26. Stavropoulos, V., Anderson, E. E., Beard, C., Latifi, M. Q., Kuss, D., \& Griffiths, M. (2019). A preliminary cross-cultural study of Hikikomori and Internet Gaming Disorder: The moderating effects of gameplaying time and living with parents. Addictive Behaviors Reports, 9, 100137. https://doi.org/10.1016/j.abrep.2018.10.001

27. Strittmatter, E., Parzer, P., Brunner, R., Fischer, G., Durkee, T., Carli, V., Hoven, C. W., Wasserman, C., Sarchiapone, M., Wasserman, D., Resch, F., \& Kaess, M. (2016). A 2-year longitudinal study of prospective predictors of pathological Internet use in adolescents. European child \& adolescent psychiatry, 25(7), 725-734. https://doi.org/10.1007/s00787-015-0779-0

28. Su, W., Han, X., Yu, H., Wu, Y., \& Potenza, M. N. (2020). Do men become addicted to internet gaming and women to social media? A meta-analysis examining gender-related differences in specific 
internet addiction. Computers in Human Behavior, 113,

106480. https://doi.org/10.1016/j.chb.2020.106480

29. Tani, I., Okada, R., Ohnishi, M., Nakajima, S., \& Tsujii, M. (2010). Japanese version of home form of the ADHD-RS: an evaluation of its reliability and validity. Research in Developmental Disabilities, 31(6), 1426-1433. https://doi.org/10.1016/j.ridd.2010.06.016

30. Tateno, M., Tateno, Y., Kamikobe, C., Monden, R., Sakaoka, O., Kanazawa, J., Kato, T. A., \& Saito, T. (2018). Internet addiction and attention-deficit/hyperactivity disorder traits among female College students in Japan. Journal of the Korean Academy of Child and Adolescent Psychiatry, 29(3), 144148. https://doi.org/10.5765/jkacap.180011

31. Tateno, M., Teo, A. R., Shiraishi, M., Tayama, M., Kawanishi, C., \& Kato, T. A. (2018). Prevalence rate of Internet addiction among Japanese college students: Two cross-sectional studies and reconsideration of cut-off points of Young's Internet Addiction Test in Japan. Psychiatry and clinical neurosciences, 72(9), 723-730. https://doi.org/10.1111/pcn.12686

32. Tokunaga, R. S. (2017). A meta-analysis of the relationships between psychosocial problems and internet habits: Synthesizing internet addiction, problematic internet use, and deficient self-regulation research. Communication Monographs, 84(4), 423-

446. https://doi.org/10.1080/03637751.2017.1332419

33. Trivedi, M. H., Rush, A. J., Ibrahim, H. M., Carmody, T. J., Biggs, M. M., Suppes, T., Crismon, M. L., Shores-Wilson, K., Toprac, M. G., Dennehy, E. B., Witte, B., \& Kashner, T. M. (2004). The Inventory of Depressive Symptomatology, Clinician Rating (IDS-C) and Self-Report (IDS-SR), and the Quick Inventory of Depressive Symptomatology, Clinician Rating (QIDS-C) and Self-Report (QIDS-SR) in public sector patients with mood disorders: a psychometric evaluation. Psychological medicine, 34(1), 73-82. https://doi.org/10.1017/S0033291703001107

34. Wang, B. Q., Yao, N. Q., Zhou, X., Liu, J., \& Lv, Z. T. (2017). The association between attention deficit/hyperactivity disorder and internet addiction: a systematic review and meta-analysis. $B M C$ psychiatry, 17(1), 260. https://doi.org/10.1186/s12888-017-1408-x

35. World Health Organization. (2018). International classification of diseases for mortality and morbidity statistics (11th Revision). Retrieved Jun 20, 2021, from: https://icd.who.int/browse11/I$\mathrm{m} / \mathrm{en}$

36. Young, K. S. (1996). Psychology of computer use: XL. Addictive use of the Internet: a case that breaks the stereotype. Psychological reports, 79(3), 899902. https://doi.org/10.2466/pr0.1996.79.3.899

37. Zhou, B., Zhang, W., Li, Y., Xue, J., \& Zhang-James, Y. (2020). Motivational but not executive dysfunction in attention deficit/hyperactivity disorder predicts internet addiction: Evidence from a longitudinal study. Psychiatry research, 285,

112814. https://doi.org/10.1016/j.psychres.2020.112814

\section{Figures}


Fig. 1

Assessed for eligibility ( $n=200,97$ males, 103 females)

\begin{tabular}{|l|l|}
\hline Potential participants ( $\mathrm{n}=129,58$ males, 71 females $)$ \\
\hline ASD (n $=47,25$ males, 22 females)
\end{tabular}

Included $(\mathrm{n}=102)$

$\operatorname{ASD}(\mathrm{n}=35,21$ males, 14 females $)$

Without ASD ( $\mathrm{n}=67,27$ males, 40 females) who diagnosed

Adjustment Disorder (16 males, 31 females)

Somatic Symptom Disorder (9 males, 4 females)

Acute Stress Disorder (1 male, 3 females)

Sleep Disorder (1 male, 2 females)

\section{Figure 1}

A flowchart of the recruitment process 